\title{
A COMPETÊNCIA DOCENTE E SUA COMPLEXIDADE DE CONCEITUAÇÃO: UMA REVISÃO SISTEMÁTICA
}

\author{
THAIS BASEM MENDES CORREA BASTOS ${ }^{1}$ \\ ORCID: https://orcid.org/0000-0002-8540-114X \\ CLODIS BOSCARIOLI ${ }^{2}$ \\ ORCID: https://orcid.org/0000-0002-7110-2026
}

\begin{abstract}
RESUMO: A definição de competência docente traz consigo uma carga social, política e cultural que muitas vezes vai de encontro a alguns conceitos educacionais, e por este motivo o termo "competência docente" é ainda muito discutido. A relevância atual dessa discussão pode ser explicitada quando observamos que as políticas públicas brasileiras utilizam o termo como embasamento para as diretrizes de formação de professores do ensino básico, sem uma consulta pública mais abrangente. Este artigo tem, portanto, como objetivo, apresentar o resultado de uma Revisão Sistemática de Literatura, buscando visões, caracterizações e construções deste conceito, aprofundando sua discussão de forma democrática e oferecendo uma reconstrução desse mesmo conceito direcionada e específica à profissão docente. Foram realizadas, em bases de dados nacionais e internacionais, pesquisas de artigos, dissertações e teses, que foram analisados sob dois aspectos; em primeiro lugar, uma análise crítica, buscando os diversos vieses, concordâncias e discordâncias, bem como a apresentação de classificações de competências que organizam e trazem um enfoque prático e direcionado à profissão docente. Em segundo lugar, uma análise de Corpus Textual com o uso do software Iramuteq identificando que palavras tais como Conhecimento, Habilidades, Atitudes, Capacidade, Recurso, Experiência e Ação, dentre outras, no campo das construções analisadas, têm relação com o conceito investigado. Finalmente, é apresentada uma proposta de consolidação e reconstrução do conceito de competência docente.
\end{abstract}

Palavras-chave: competência docente, conceito, profissão docente.

\section{TEACHING COMPETENCE AND ITS COMPLEXITY OF CONCEPT: A SYSTEMATIC REVIEW}

\begin{abstract}
The definition of teaching competence carries social, political and cultural weights that often go against some educational concepts, and for this reason the term "teaching competence" is still very much discussed. The current relevance of this discussion can be revealed by observing how Brazilian public policies use the term as a cornerstone for primary education teacher training guidelines, without a more comprehensive public consultation. Therefore, this article intends to present the Results of a Systematic Literary review, searching for visions, definitions and conceptions, extending its discussion democratically and presenting a reconstruction of that same concept, specifically directed to the teaching
\end{abstract}

\footnotetext{
${ }^{1}$ Universidade Estadual do Oeste do Paraná. Foz do Iguaçu, PR, Brasil. < thaisbasem@gmail.com>

${ }^{2}$ Universidade Estadual do Oeste do Paraná. Cascavel, PR, Brasil. <boscarioli@gmail.com> Educação em Revista|Belo Horizonte|v.37|e235498/2021
} 
profession. Researches on articles, dissertations and theses were carried out from national and international databases, which were analyzed under two aspects: first, a critical analysis, looking for the several angles, agreements and disagreements, as well as presenting categorizations of competences that organize and bring a practical and focused approach to the teaching profession. Second, a text corpus analysis with the use of the Iramuteq software, recognizing that words such as Knowledge, Skills, Attitudes, Capacity, Resource, Experience and Action, among others, in the field of the analyzed conceptions, are related to the investigated concept. Finally, a suggestion for consolidating and reconstructing the concept of teaching competence is presented.

Keywords: teaching competence, concept, teaching profession.

\section{COMPETENCIA DOCENTE Y SU COMPLEJIDAD DE CONCEPTO: UNA REVISIÓN SISTEMÁTICA}

RESÚMEN: El concepto de competencia docente trae consigo una carga social, política y cultural, que a menudo va en contra de algunos conceptos educativos, por esta razón el término "competencia docente" todavía es muy discutido. La relevancia actual de esta discusión se puede aclarar cuando observamos que las políticas públicas brasileñas utilizan el término como base para las directrices de formación docente de educación básica, sin una consulta pública más amplia. Este artículo, por lo tanto, tiene como objetivo presentar el resultado de una Revisión Sistemática de Literatura, buscando visiones, caracterizaciones y construcciones de este concepto, con el objetivo de profundizar la discusión de una manera democrática y ofrecer una reconstrucción del mismo concepto de una manera específica y direccionada a la profesión docente. Se realizaron investigaciones en bases de datos nacionales e internacionales de artículos, disertaciones y tesis, que se analizaron bajo dos aspectos: inicialmente un análisis crítico, buscando las diversas tendencias, concordancias y desacuerdos, además, se presentan clasificaciones de competencias que organizan y aportan un Enfoque práctico y dirigido a la profesión docente. El segundo análisis es un análisis de Corpus Textual utilizando el software Iramuteq que identifica palabras como: Conocimiento, Habilidades, Actitudes, Capacidad, Recurso, Experiencia y Acción, entre otras, dentro de las construcciones analizadas, están relacionadas con el concepto investigado. Finalmente, se presenta una propuesta para consolidar y reconstruir el concepto de competencia docente.

Palabras clave: competencia docente, concepto, profesión docente. 


\section{INTRODUÇÃO}

A competência docente é um termo que traz opiniões dúbias pois, se por um lado parece ser pouco profundo, quando pensamos na complexidade da profissão docente, por outro é o termo assumido atualmente nos documentos nacionais, tanto nos desenvolvimentos curriculares (BRASIL, 2017) - formação por competências da Base Nacional Comum Curricular - quanto nas diretrizes de formação de professores do Ensino Básico (MEC, 2019).

Este posicionamento nacional frente à educação pode fomentar a discussão sobre competência docente, abordando a prática profissional dos professores e reforçando os saberes plurais e temporais, considerados estratégicos. Esses saberes são ainda pouco explorados como um conjunto de conhecimentos direcionados ao saber-fazer e de experiências adquiridas - pensando-se ainda em sua aplicação e reflexão como competências sociais e ambientais -, sendo atualmente incorporados na prática educacional sem serem produzidos ou legitimados para este fim (TARDIF, 2014).

A análise desses saberes, bem como a organização de enunciados que aproximem mais a prática docente de questões conceituais das demais profissões, respeitando-se sua singularidade, tem ocorrido em diversas discussões acadêmicas e científicas, trazendo um conceito mais próximo dos que são utilizados pela corrente da psicologia organizacional, no que diz respeito à organização do trabalho e de suas perspectivas de competências técnicas e comportamentais necessárias para a boa execução de uma atividade profissional.

Esta discussão é ampla e abrange diversos aspectos sociais, políticos e especialmente educacionais, esbarrando de forma inequívoca na formação docente, especialmente quando se enfoca nas questões de conjunto de saberes para ensinar (CONCEIÇÃO; SOUZA, 2012). A definição de "competência" deve ser delimitada quando se pretende aproximar a teoria da prática profissional diária. A literatura de gestão em recursos humanos e competências - mais especificamente, Fleury e Fleury (2001) e Hipólito (2000), Dutra (2001) e Gonçalvez et al. (2016) - define as competências como o conjunto de conhecimentos, habilidades e atitudes (CHA) que justificam um alto desempenho e resultados. Este conceito é resultado de uma evolução histórica que se inicia em 1973 com David McClelland, que apresenta um estudo no qual diferencia as "aptidões" das "competências". Enquanto a aptidão é inata ao indivíduo, a competência decorre de um processo de aprendizagem, e, neste processo, uma aptidão pode ser aprimorada e desenvolvida com conhecimentos - informações sobre o que é necessário para desempenhar uma atividade - e habilidades - saber efetivamente realizar uma atividade ou colocar em prática uma aptidão.

A competência, neste momento, passa a ser definida como a característica subjacente à pessoa e que é casualmente relacionada ao desempenho superior na realização de uma tarefa (FLEURY; FLEURY, 2001). Além disso, ocorre um deslocamento do que era puramente considerado como um estoque (ou repertório) de conhecimentos e habilidades para a forma (ou maneira) com que a pessoa aplica esse repertório em seu cotidiano, incluindo então um novo componente das competências: a atitude (GONÇALVEZ et al. 2016), o que evidencia que a competência pode ser entendida como um rol de Conhecimentos, Habilidades e Atitudes (CHA). Alinhado a este conceito, Behar (2013) aponta que apenas o adquirir conhecimentos ou dominar algumas técnicas não é mais suficiente para ser competente; o que importa é, sim, como os conhecimentos e as técnicas se refletem nas atitudes frente aos desafios reais, o que, por si só, já nos leva para as questões das atitudes e das ações. Estas, por sua vez, como ainda afirma a autora, são uma forma de conhecimento autônomo que não necessariamente nos leva à tomada de consciência dos meios utilizados para um determinado fim, sendo que a compreensão ocorrerá após o fazer, quando ele é reconstruído de forma reflexiva. 
Nesse sentido, os conhecimentos na profissão docente não são apenas os conteúdos ou as teorias, mas a construção de saberes docentes muito mais complexos, fruto da experiência, participação e interação com a comunidade escolar no âmbito das ações. A compreensão das competências docentes dentro de uma proposta de competências profissionais já pode ser verificada desde a década de $2000 \mathrm{em}$ diversas matrizes e frameworks dos países membros da Organização para a Cooperação e Desenvolvimento Econômico (OCDE), a citar a Noruega, a Alemanha, a Espanha, Portugal, os Estados Unidos e a Holanda, e em políticas de desenvolvimento educacional de países parceiros, como a África do Sul e a Costa Rica (categoria em que também se inclui o Brasil). No caso brasileiro, foi somente em 2019 que este posicionamento se fez mais claro, embora ainda encontre diversas resistências culturais.

Por esses motivos, compreendemos que verificar e aprofundar as discussões sobre o termo competência docente é ainda uma questão atual e necessária para subsidiar temas como a formação docente e os descritivos e matrizes profissionais para professores, sendo este, então, o objetivo do presente artigo: identificar as discussões atuais, buscando as concordâncias e discordâncias, bem como realizar uma reconstrução do conceito de competência como proposta mais abrangente. Essas discussões serão efetivadas, evidentemente, fazendo-se uma análise de publicações e estudos recentes com vistas a uma reconstrução conceitual, inspirada nas premissas do Agir Comunicativo, que oferece uma linha epistemológica crítica e democrática, considerando pesquisador e ouvinte (todo aquele que recebe a comunicação, seja ela em qualquer formato - o leitor, nesse caso, também é um ouvinte) como partes atuantes no processo de construção da comunicação e do conhecimento, sejam elas dialógicas ou práticas (HABERMAS, 1989), na busca de uma descrição que abrace as especificidades e complexidades da profissão.

Com esse direcionamento, este artigo está organizado em uma apresentação geral e uma contextualização; em seguida, apresenta-se o registro da metodologia de pesquisa realizada, na qual se identificam os principais aspectos da Revisão Sistemática de Literatura (RSL), metodologia escolhida para a realização deste estudo. A terceira seção aborda as discussões e reflexões acerca dos resultados obtidos, utilizando-se de metaestudo e síntese textual narrativa. Finalmente, a última seção traz uma proposta de reconstrução do conceito de competência docente com base nos documentos analisados.

\section{METODOLOGIA DA PESQUISA}

Para esta análise, optamos pelo método de Revisão Sistemática de Literatura investigando o conceito de competência docente. A opção pela metodologia RSL dá-se pela clareza dos métodos da pesquisa, o que resulta em uma síntese de diversos estudos e a análise crítica organizada (SAMPAIO; MANCINI, 2007), além da sistematização das buscas em bases de dados eletrônicas, o que oferece uma relevância de conteúdo em tempo reduzido, quando bem realizada.

Os instrumentos encontrados foram tratados como dados primários da análise, passando por três momentos: uma primeira análise de qualidade, quantificando e avaliando numericamente cada um dos instrumentos encontrados (COSTA; ZOLTOWSKI, 2014; MORANDI; CAMARGO, 2015); uma segunda análise de organização dos dados seguindo o processo de metaestudo e síntese crítica interpretativa, suportados pelos preceitos metodológicos habermasianos de análise reconstrutiva, buscando organizar as informações qualitativas de forma estruturada e refinando as questões da pesquisa; e, por último, uma análise de constructos e vocábulos no formato de framework síntese (MORANDI; CAMARGO, 2015), elaborando um produto final cujo objetivo é conceituar competência docente.

Para a condução desta pesquisa inicial, serão considerados os oito passos propostos por Ramos et al. (2014), que adaptam de forma didática a RSL às ciências da Educação: (1) Objetivos; (2) Equações de Pesquisa; (3) Âmbitos da Pesquisa; (4) Critérios de Inclusão; (5) Critérios de Exclusão; (6) Critérios de Validade Metodológica; (7) Resultados; e (8) Tratamento dos Dados.

\section{Objetivos e Equações de Busca}

O objetivo é o que define o produto resultante do método da RSL (BRIZOLA; FANTIN, 2016). Dessa forma, direcionamos nossa RSL com o propósito de identificar quais os principais conceitos 
utilizados como competência docente entre 2013 e 2018 e verificar quais foram as discussões realizadas sobre o tema, buscando similaridades e divergências. Os dados coletados serão analisados sob a ótica de consolidação, perseguindo um conceito delimitado e autocontido. Tais análises vão oferecer um mapa compilado dos dados de forma coerente, direcionado à teoria analisada. O objetivo da RSL deve ter, ainda, de forma explícita, perguntas abertas para que sejam respondidas com informações qualitativas provenientes da análise de dados das fontes pesquisadas (MORANDI; CAMARGO, 2015). Com este viés, foram elaboradas quatro questões de pesquisa para nortear a RSL, que podem ser analisadas de forma independente e que trataram também da heterogeneidade da busca, a saber:

Q1. Quais os conceitos de competência docente identificados?

Q2. Quais as similaridades e divergências entre os conceitos de competência docente? forma clara?

Q3. Quais os embasamentos teóricos para a escolha deste conceito? Foram identificados de

Q4. Qual a consolidação possível de um conceito único aproveitando as similaridades encontradas e repensando as divergências?

Ainda com o intuito de direcionar a pesquisa e para responder a essas questões, foram demarcados os quatro aspectos da RSL, que servem de consolidação do protocolo de busca para este trabalho: População, Intervenção, Controle e Resultados (KITCHENHAM, 2004), delimitando então que serão pesquisados artigos, teses e dissertações que tratem explicitamente do tema competência docente (População), que tragam de forma expressa o conceito de competência utilizado para o estudo (Intervenção) para ser comparado com o conceito de competência de Fleury e Fleury (2001, p. 185), pensado "como conjunto de conhecimentos, habilidades e atitudes (isto é, conjunto de capacidades humanas) que justificam um alto desempenho" (Controle), para posterior encaminhamento de um conceito (Resultados).

Para atingir o Resultado, foram elaboradas Equações de Pesquisa, também conhecidas como strings de busca, levando-se em consideração os termos centrais utilizados, seus sinônimos e as variações relevantes para a pesquisa (KITCHENHAM, 2004). Definimos três termos centrais: "Competência", "Professores" e "Conceito" e suas variações, conforme o Quadro 1.

\begin{tabular}{|l|l|l|}
\multicolumn{2}{l}{ Quadro1-Equações de busca utilizadas. } \\
\hline Código & Idioma & Descrição \\
\hline Eq-ENG & Inglês & $\begin{array}{l}\text { (Concept) AND (Teacher) AND (Skill) } \\
\text { OR (Competence) OR (Competency) }\end{array}$ \\
\hline Eq-POR & Português & $\begin{array}{l}\text { (Conceito) AND (Competência) AND } \\
\text { (Docente) OR (Professor) }\end{array}$ \\
\hline
\end{tabular}

Fonte: Elaborado pelos autores.

\section{Âmbito de Pesquisa e Critérios de Inclusão e Exclusão}

O âmbito de pesquisa é a ambiência em que se delimitam as estratégias de busca para delinear que tipo de estudos serão considerados (COSTA; ZOLTOSKI, 2014; RAMOS et al., 2014; MORANDI; CAMARGO, 2015) e quais estratégias serão utilizadas no momento da pesquisa ou diretamente no motor de busca.

Para a análise do conceito de competência docente, foram considerados documentos em português e inglês, independentemente dos países de publicação, que tenham os termos agregados: "Competência", "Docente" e "Tecnologia". Como estratégia para esta RSL, utilizamos somente fontes de pesquisa eletrônicas, buscando teses, dissertações e artigos (neste caso, quando informado, serão considerados apenas os revisados por pares), publicados entre 2013 e 2018, em inglês e português, disponíveis integralmente e gratuitamente via web no processo de busca por exaustão de conteúdos de educação, quando possível direcionados para a educação superior e/ou formação de professores. 
saber:

Foram selecionadas oito bases de dados a serem utilizadas, sendo quatro internacionais, a

- Biblioteca Digital do IEEE < https://ieeexplore.ieee.org/Xplore/home.jsp>;

- Biblioteca Digital da ACM <https://dl.acm.org>;

- Springer Link < https://link.springer.com/>;

- ERIC - Education Resources Education Center <https://eric.ed.gov/>.

As bases de dados nacionais selecionadas foram:

- Portal de Busca Integrada USP < http://www.buscaintegrada.usp.br/>;

- Banco de teses da Capes <http://catalogodeteses.capes.gov.br/catalogo-teses>;

- Biblioteca Digital Brasileira de Teses e Dissertações < http://bdtd.ibict.br>;

- The Scientific Electronic Library Online - SciELO < http://www.scielo.br/>.

Os Critérios de Inclusão e Exclusão são os filtros utilizados para a seleção dos artigos que serão lidos integralmente e farão parte do resultado da investigação, definindo assim a relevância do documento para a pesquisa em questão (COSTA; ZOLTOWSKI, 2014). Para a aplicação desses critérios, é realizada a leitura em método de screening, que trata da leitura superficial dos documentos selecionados, ou seja, a leitura de título, palavras-chave e resumo (MORANDI; CAMARGO, 2015) na busca por similaridades.

Como Critério de Inclusão (CI), foram considerados:

a) documentos que no método de screening apresentem expressamente os termos das equações de pesquisa;

b) que os métodos de pesquisa sejam qualitativos ou mistos;

c) que tragam em seus resumos, títulos ou palavras-chave indicadores teóricos sobre a construção do conceito de competência docente.

Como Critério de Exclusão (CE), foram considerados:

d) documentos que no método de screening não apresentem expressamente os termos das equações de pesquisa;

e) que os métodos de pesquisa sejam quantitativos;

f) que não tragam indicadores teóricos sobre a construção do conceito de competência docente ou apenas tratem competências específicas;

g) que tragam apenas a descrição da competência técnica, e não de seu conceito.

Após a definição dos CI e CE, a configuração teórica do trabalho de pesquisa da RSL foi finalizada, sendo que as demais etapas já fazem parte da operacionalização da pesquisa com a aplicação dessa estratégia de busca.

\section{Critérios de Validade Metodológica e Resultados}

A validade metodológica é a aplicação de todos os critérios definidos até aqui, de forma a explicitar o percurso metodológico realizado pelo pesquisador, garantindo uma estrutura replicável, além de ser o momento de organização e registro das buscas realizadas (SAMPAIO; MANCINI, 2007; RAMOS et al., 2014). As buscas foram realizadas entre os meses de setembro e outubro de 2018, individualmente em cada uma das bases referidas, resultando na seguinte estrutura quantitativa de materiais.

Para registro, foi realizada a primeira busca sem a aplicação de nenhum dos filtros da estratégia de pesquisa nos âmbitos do estudo, sendo em seguida incluídos estes filtros nos rastreios de cada base de dados, considerado o primeiro refino. Em seguida, foram aplicados os critérios de inclusão e exclusão como um segundo refinamento, como pode ser observado na Figura 1. 
Figura 1: Número de documentos obtidos em cada etapa da RSL.

\begin{tabular}{|c|c|c|c|}
\hline Bases de Dados & $\begin{array}{c}\text { Pesquisa Inicial } \\
\text { Pesquisa sem as estratégias } \\
\text { de busca definidas }\end{array}$ & $\begin{array}{c}\text { Refino } 1 \\
\text { Aplicação dos filtros } \\
\text { das estratégias de busca }\end{array}$ & $\begin{array}{c}\text { Refino } 2 \\
\text { Aplicação dos Critérios } \\
\text { de Inclusão e Exclusão }\end{array}$ \\
\hline IEEE & 7. 388 & 54 & 1 \\
\hline $\mathrm{ACM}$ & 149 & 78 & 0 \\
\hline SpringerLink & 420.216 & 225 & 5 \\
\hline ERIC & 15.050 & 38 & 4 \\
\hline Biblioteca Integrada da USP & 1.567 & 48 & 3 \\
\hline CAPES & 97 & 39 & 11 \\
\hline BDTD & 2365 & 31 & 0 \\
\hline Scielo & 12 & 7 & 3 \\
\hline Total de Documentos & 446.844 & 520 & 27 \\
\hline
\end{tabular}

Fonte: Desenvolvido pelos autores.

Os 27 documentos selecionados foram ainda qualificados de acordo com a relevância para as análises. Esta avaliação deu-se em quatro critérios: diversidade de autores embasando a teoria apresentada (C1); aderência às questões de pesquisa (C2); apresentação formalizada de um conceito de competência (C3); e amplitude da discussão proposta pelo trabalho (C4).

Os critérios foram avaliados em três graduações: zero, quando não atendia o quesito; um, quando atendia parcialmente ou com baixa qualidade; e dois, quando atendia completamente ou com alta qualidade. Esses valores servirão de indicadores-peso para a ponderação de avaliação final, sendo que cada quesito correspondeu a um quarto da nota final, que foi de zero a dez, seguindo a Equação 1:

$$
(\mathrm{C} 1 \times 0,25)+(\mathrm{C} 2 \times 0,25)+(\mathrm{C} 3 \times 0,25)+(\mathrm{C} 4 \times 0,25)) \times 10 \div 2=\text { NOTA FINAL (Equação 1) }
$$

As notas ponderadas e os valores atribuídos como peso por critério estão apresentadas no Quadro 2. Pode-se observar que a RSL retornou materiais na maioria acima da média em relação à qualidade de conteúdo, com destaque de seis dos materiais que apresentam uma profundidade superior, bem como uma ampla abordagem, inclusive histórica, do tema desta pesquisa.

Quadro 2 - Classificação relativa à qualidade dos instrumentos de pesquisa.

\begin{tabular}{|l|l|l|l|l|l|}
\hline Documento & C1 & C2 & C3 & C4 & $\begin{array}{l}\text { Avaliação } \\
\text { final }\end{array}$ \\
\hline COSTA, 2013 & 2 & 2 & 2 & 2 & 10 \\
\hline ESPINDOLA, 2015 & 2 & 2 & 2 & 2 & 10 \\
\hline FAUTH et al., 2018 & 2 & 2 & 2 & 2 & 10 \\
\hline MARQUES, 2017 & 2 & 2 & 2 & 2 & 10 \\
\hline MEDEIROS, 2016 & 2 & 2 & 2 & 2 & 10 \\
\hline URZEDO, 2017 & 2 & 2 & 2 & 2 & 10 \\
\hline ALBERTO, 2015 & 2 & 2 & 1 & 2 & 8,75 \\
\hline CASSUNDÉ et al., 2017 & 2 & 1 & 2 & 2 & 8,75 \\
\hline BANDEIRA; SOUZA, 2014 & 1 & 1 & 2 & 2 & 7,5 \\
\hline GRIFFIOEN, 2018 & 1 & 1 & 2 & 2 & 7,5 \\
\hline GUTSU et al., 2016 & 2 & 1 & 1 & 2 & 7,5 \\
\hline KIM et al., 2018 & 1 & 1 & 2 & 2 & 7,5 \\
\hline \multicolumn{2}{|l|}{ Educação em Revista|Belo Horizonte|v.37|e235498/2021 } & \\
\hline
\end{tabular}




\begin{tabular}{|l|l|l|l|l|l|}
\hline DAM et al., 2018 & 1 & 1 & 1 & 2 & 6,25 \\
\hline ELBARBARY, 2015 & 1 & 1 & 2 & 1 & 6,25 \\
\hline GORZONI; DAVIS, 2017 & 1 & 1 & 1 & 2 & 6,25 \\
\hline GUIMARÃES, 2013 & 2 & 1 & 0 & 2 & 6,25 \\
\hline ANDRADE, 2015 & 1 & 1 & 1 & 1 & 5 \\
\hline RIE et al., 2018 & 1 & 1 & 0 & 2 & 5 \\
\hline SEVERO, 2016. & 1 & 1 & 0 & 2 & 5 \\
\hline KAZU; DEMIRALP, 2016 & 1 & 1 & 0 & 1 & 3,75 \\
\hline COSTA, 2018 & 0 & 1 & 1 & 0 & 2,5 \\
\hline GOMES, 2018 & 1 & 1 & 0 & 0 & 2,5 \\
\hline MAULANA et al., 2016 & 2 & 0 & 0 & 0 & 2,5 \\
\hline OLIVEIRA, F. 2017 & 1 & 0 & 0 & 1 & 2,5 \\
\hline OLIVEIRA, A. 2017 & 0 & 0 & 0 & 1 & 1,25 \\
\hline SILVA, 2016 & 1 & 0 & 0 & 0 & 1,25 \\
\hline SERGIS; SAMPSON, 2016 & 0 & 0 & 0 & 0 & 0 \\
\hline
\end{tabular}

Fonte: Elaborado pelos autores. ${ }^{3}$

Para a discussão de metaestudo e síntese textual narrativa, foram descartados os conteúdos com avaliação final menor do que três pontos, resultando em 20 textos analisados. Vale ressaltar que a maioria dos documentos não tem o tema competência docente como fim, mas como meio ou base das suas pesquisas e discussões.

\section{ANÁLISE DO CONCEITO DE COMPETÊNCIA DOCENTE}

A leitura integral dos documentos deixa claro para nós que a discussão sobre o conceito de competência ainda está longe de chegar a uma conclusão. Talvez essa conclusão nem seja possível, tendo em vista que esse conceito tem em si uma característica dinâmica, polissêmica e que se adapta ao contexto em que está inserido.

A história da conceituação de competência e sua aproximação com as práticas pedagógicas não é recente, especialmente quando se trata da construção de currículos para a formação profissional. Nesse âmbito, é relevante inter-relacionar correntes lógico-filosóficas, especialmente por sabermos que o tema em questão é controverso no ambiente educacional, e essa inter-relação pode trazer luz a este assunto delicado (MEDEIROS, 2016).

Segundo Alberto (2015), a aplicação do termo competência no contexto educacional tem origem na Idade Média e é intensificada com a racionalidade moderna, o capitalismo e a expansão da industrialização, que determinou inúmeras mudanças na sociedade, nas divisões de trabalho e nas necessidades de novas capacidades dos trabalhadores para tarefas cada vez mais complexas. Esta origem na relação capital-trabalho-educação oferece-nos um direcionamento para as questões da baixa aceitação do termo, especialmente quando pensamos que a educação é também responsável pelo desenvolvimento do pensar crítico e da tomada de consciência sobre si mesmo e sobre as relações sociais em que se está inserido. Segundo o autor, quando a Educação fica somente a serviço do capital e tende a minimizar os aspectos críticos para que as massas possam servir como mão de obra, o termo competência pode adquirir uma conotação de achatamento das capacidades dos sujeitos (ALBERTO, 2015).

Nesse aspecto, é válido ressaltar que mais autores aludem que o conceito de competência é sempre provisório, que não se pode ter a respeito dele uma definição fechada e absoluta (ALBERTO, 2015; ESPINDOLA, 2015), tendo em vista que ele se molda aos interesses da época em que está sendo

\footnotetext{
${ }^{3}$ Alguns autores - Costa (2018), Maulana et al. (2016), Oliveira A. (2017) e Sergis; Sampson (2016) - constam do Quadro 2 e fizeram parte do estudo como materiais lidos; embora não tenham sido citados no texto por terem avaliação inferior a 3 e pelo fato de o conteúdo não estar alinhado aos parâmetros da RSL, eles constam das Referências, a fim de se manterem os procedimentos da RSL com clareza e coerência quanto ao material utilizado. 
forjado (SEVERO, 2016). Da mesma maneira, não se deve partir de um único viés sob o risco de não se compreender a complexidade e a dimensionalidade de suas aplicações (ALBERTO, 2015; SEVERO, 2016).

Apresentando outra ótica, Medeiros (2016) trata da conceituação de competência direcionada para as inter-relações e oferece uma proposta consolidada partindo de um embasamento epistemológico crítico baseado em diversos autores. Mesmo compreendendo que existem conotações carregadas de juízos políticos, sociais e históricos dos termos, busca um conceito consolidado mais amplo. Essas conotações levam-nos a compreender que abordar uma linha filosófica e epistemológica é apropriado.

Podemos, então, segundo Medeiros (2016), identificar que o conceito de competência tem inicialmente uma Lógica Condutivista, originária dos Estados Unidos, que caracteriza competência como "aquelas disposições necessárias para alcançar um desempenho superior ou performance e de habilidades mínimas, aquelas que implicam um resultado mediano ou fraco" (MEDEIROS, 2016, p.1033) e define uma diferença entre competência e habilidade, sendo uma mais profunda que a outra, ou seja, diferem apenas por uma "questão de grau". Essa abordagem é ainda utilizada em sua íntegra e sem variações em muitos estados dos Estados Unidos, inclusive quando se trata de competência docente, sendo que no país não existe uma hegemonia quanto a esse termo (MARQUES, 2017).

Urzedo (2017) também aponta que a competência nos estados norte-americanos pode ter significados distintos, o que concorda com a linha de pensamento de dinamismo e polissemia do termo: em alguns momentos, refere-se às características dos indivíduos (especialmente no que tange ao CHA Conhecimentos, Habilidades, Atitudes -, incluindo Personalidade e Motivações); em outros momentos, relaciona-se diretamente com as atividades produtivas e com os resultados esperados do trabalho, sendo que, de forma geral, ela indica um desempenho superior do indivíduo, que pode ser entendido então como excelência.

A segunda lógica abordada por Medeiros (2016) é a Funcionalista, que delineia as competências para o caráter polivalente dos trabalhadores dentro de um sistema de trabalho (seja uma empresa, departamento, escola ou sala de aula) e que pode ser caracterizada como conhecimentos, habilidades e atitudes dos trabalhadores que geram resultado para a organização, sendo este modelo um dos mais utilizados no Canadá e no Brasil. A Lógica Funcionalista tem sinergia também com a abordagem francesa, que enfoca diretamente a capacidade de mobilização de recursos pessoais, compreendendo e dominando situações imprevisíveis e instáveis, transpondo conhecimentos para a prática profissional, além de considerar a relação entre três dimensões: conhecimento factual - saber e conhecimento; experiência - saber fazer e saber agir; e comportamento - saber ser e a capacidade de se adaptar (MARQUES, 2017; URZEDO, 2017).

Por fim, em sua análise teórica, Medeiros (2016) traz a Lógica Cognitiva/Construtivista citando Piaget e Inhelder ao apresentar um conceito de competência mais distante dos poderes dominantes da sociedade (empresas e Estado, por exemplo) e com um enfoque que respeite as interações sociais e os aspectos psicológicos individuais, bem como a capacidade do sujeito de responder a um estímulo externo, incluindo aqui a questão do ambiente. O conceito, segundo o autor, pode ser visto como o saber, saber-fazer e saber-ser, sendo isso direcionado pela "evidência de necessidades resultantes da coordenação de ações, a retroatividade entre as relações interindividuais, as ações entre grupos, num certo entorno natural e social e as configurações das situações de trabalho e capacitação" (MEDEIROS, 2016, p. 1036).

Porém, mesmo com esta última definição, a utilização do termo acaba muitas vezes sendo a descrição, de forma superficial, apenas de atividades, conteúdo técnico e responsabilidades, o que mantém o caráter exploratório de força de trabalho. A intenção, dessa forma, é chegar a um conceito mais amplo e que seria mais aceito quando se aproximasse das discussões pedagógicas, mas que ainda carece de aprofundamento, numa Lógica Sócio-Crítica Interacional, baseada na epistemologia genética de Piaget, na epistemologia de Marx, na perspectiva de Vigotsky e na tradição da Sociologia Crítica, além de recorrer à hermenêutica como viés de análise. Com este embasamento, ele sugere que a competência pode ser descrita como "Um processo enactivo através do qual produzimos um arranjo heurístico- 
cognitivo e teórico-prático adequado a solução de problemas colocados por situações imprevistas e por imprevistos colocados por situações rotineiras" (MEDEIROS, 2016, p. 1039).

Urzedo (2017) traz uma discussão semelhante, e, apesar de as correntes epistemológicas atuais terem grande importância, não são as únicas que subsidiam a construção conceitual de competência, especialmente quando se direcionam para a prática docente. Ele discorre sobre as abordagens diferenciadas, sociais e relacionais, iniciando com uma crítica ao conceito de CHA, que é muito tecnicista, acrescentando a ele outros aspectos, tais como personalidade individual, ambiente de trabalho, autonomia e responsabilidade. Sustentado em autores como Ruas, Sparrow e Bognanno, Ropé e Tanguy, Wittorsk, dentre outros, esse autor aborda competência de modo complexo e não apenas como um esquema único, mas um conjunto de esquemas, e introduz conceitos mais complexos das competências organizacionais como subsídio para a competência docente, subdividindo-as em grupos de competências: cognitivas/conhecimento, funcionais, pessoal/comportamental e ética/valores.

Essa divisão aproxima-se do conceito proposto por Kim et al. (2018), que realizaram um estudo direcionado ao desenvolvimento acadêmico dos professores na Ásia, abordando a competência como o conjunto de conhecimentos, habilidades e valores com base em estudos anteriores que formatam frameworks de competências profissionais docentes e nas opiniões dos próprios sujeitos. Nos frameworks propostos por Kim et al. (2018), somente não aparecem as questões comportamentais encontradas nas propostas de Urzedo (2017).

Quando aborda diretamente as competências docentes, Urzedo (2017) enfoca a complexidade da profissão professor e, de forma intrínseca, promove uma reflexão da prática docente e da permeabilidade das competências na prática diária. Ele utiliza a terminologia "saberes" como um sinônimo para competência nesse cenário, mostrando-nos que a profissão docente é como qualquer outra, sendo que professores devem ter os conhecimentos e as habilidades exigidas para que possam desempenhar com qualidade as suas funções. $\mathrm{O}$ autor salienta ainda que, quando avaliado, o professor competente, que apresenta um elevado grau de desempenho em sua prática, faz com que seu trabalho tenha reflexo direto na aprendizagem do aluno, com elevado nível de apreensão e significado.

Diferentemente dos demais autores, Griffioen (2018) considera competência como um conceito já consolidado, destacando que não há mais necessidade de um debate conceitual sobre o assunto e, de forma genérica, caracteriza-o como atributos pessoais, conhecimento, habilidades e experiência - sendo que os atributos pessoais são características pessoais e comportamentais, como entusiasmo, perseverança, integridade - e recomenda que o perfil profissional de professores seja definido pela relação das competências com as atividades profissionais, tais como colaboração com estudantes, pesquisa, supervisão e orientação. Severo (2016) e Gorzoni e Davis (2017) também compartilham da ideia de que a discussão do conceito de competência já é algo ultrapassado.

Segundo Severo (2016), a reflexão atual deve ser sobre a profissionalidade docente e discorre sobre um tema delicado, assinalando que:

[...] expressões como "epistemologia da prática, professor-reflexivo, prática-reflexiva, professor pesquisador, conhecimentos e competências" (ALVES, 2007, p. 265) são comumente empregadas para designar os modelos de pensamento do professor, o tipo de prática desempenhada por ele e a natureza dos subsídios que devem fomentar a sua atuação nos contextos de inserção profissional (SEVERO, 2016, p. 264).

Nessa linha de pensamento, esse autor não conceitua a competência, mas promove uma discussão sobre a importância de se reverem e se repensarem os conceitos à luz da modernidade, especialmente pelo fato de a pedagogia ser dinâmica e trazer enfoques apropriados às problemáticas contemporâneas. Profissionalidade Docente, termo ainda em discussão no Brasil, é abordado também por Gomes (2015) e Gorzoni e Davis (2017), sendo que se assemelha à discussão de perfil profissional (GRIFFIOEN, 2018), ou identidade profissional docente (KIM et al., 2018), trazendo um debate mais sistêmico sobre o papel do professor, de sua autonomia e da especificidade da profissão. A Profissionalidade está relacionada às características inerentes à ação docente, ou seja, à ação de ensinar, característica esta que permanece ao longo da evolução histórico-social e se embasa na construção de competências e no desenvolvimento de habilidades próprias ao ato de ensinar, adquiridas nas formações 
e nas experiências de trabalho do professor (GORZONI; DAVIS, 2017), sendo que, nesse aspecto, as competências são assim descritas:

A competência profissional refere-se aos recursos intelectuais empregados na construção do repertório de conhecimentos profissionais, habilidades e técnicas para desenvolver a ação didática, a análise e reflexão sobre a prática e condição de intervir no meio externo para favorecer o ensino (GORZONI; DAVIS, 2017, p. 1400).

Todos os conceitos envolvidos na Profissionalidade Docente são reflexo dos próprios docentes e, por isso, são podem ser descritos como modelos de pensamento (SEVERO, 2016), que também podem ser entendidos como mindsets. O mindset (em tradução livre: configuração mental) é um modelo mental normalmente desenvolvido por pesquisas realizadas diretamente com os sujeitos envolvidos, nas quais eles demonstram quais são suas crenças cotidianas que interferem diretamente na forma com que eles pensam e agem (RIE et al., 2018). Esses modelos trazem informações interessantes ao entendimento de como os sujeitos compreendem sua própria realidade.

Em pesquisa com professores em formação na Áustria, Rie et al. (2018) buscaram discutir sobre as habilidades e competências de professores para a elaboração de um mindset. Nesse estudo, novamente o conceito de competência não é mais o foco da discussão; eles abordam uma visão mais ampla da profissão como um todo, sendo que os pilares que se sobressaíram foram a capacidade de aprender, seja um conteúdo específico, sejam técnicas de sala de aula (aspectos profissionais e didáticos); o desenvolvimento de habilidades interpessoais adequadas ao processo de ensino; e também a personalidade individual, que, para os entrevistados neste estudo, não são características "aprendíveis", mas, sim, aspectos comportamentais e motivadores inerentes à pessoa.

Oliveira F. (2017) também traz uma discussão semelhante sobre o perfil profissional de professores, ressaltando os saberes docentes (incluindo-se aqui o saber-fazer e o saber-ser); a preparação técnica, científica e social; a capacidade de aplicar seus saberes de forma prática (didática e vivência); e as reflexões críticas sobre o ambiente social e também sobre seu trabalho, que juntas são mobilizadas para a prática docente.

Em outro viés, Dam et al. (2018) oferecem em seu trabalho uma discussão interessante sobre as reformas educacionais e, mesmo que não conceituem competência, promovem uma discussão sobre a importância das questões comportamentais para a implantação de reformas educacionais, argumentando que

Uma proposta de reforma só pode ter sucesso se os professores expandirem e modificarem seu repertório comportamental de acordo com a reforma. No entanto, mudar as práticas e rotinas regulares dos professores provou ser muito difícil. Para uma mudança comportamental bemsucedida, não é suficiente simplesmente oferecer aos professores novos conhecimentos e habilidades; eles também precisam estar motivados para mudar. A literatura sobre mudança comportamental mostra que as pessoas precisam tanto da habilidade quanto da vontade de mudar seu comportamento com sucesso (DAM et al., 2018, p. 370, tradução nossa).

Os autores consideram que a prática profissional docente, especialmente quando se refere à implantação de reformas, precisa ser pautada em conhecimentos, habilidades e motivadores comportamentais, e estes termos ainda precisam ser aprofundados e discutidos. Além disso, entendem a prática docente como um conjunto de competências, e por isso é possível extrapolar a discussão não apenas para os momentos de reforma, como também para toda a prática docente e desta forma também para o conceito de competência, o que nos leva a observar outras discussões atuais sobre o termo.

Diversos trabalhos e pesquisas, tais como Costa (2013); Bandeira e Souza (2014); Andrade (2015); Espindola (2015) e Gomes (2015), têm-se baseado em Perrenoud (1999) e seu conceito de competência. Uma discussão igualmente importante sobre o conceito de competência de Perrenoud é o que diz respeito à flexibilidade possível dos significados, o que se explica especialmente pela complexidade da realidade em que a educação está inserida. Andrade (2015) ressalta que as competências têm como objetivo a resolução de problemas complexos, e isso explica as diferenças encontradas na 
terminologia de Perrenoud. Nesse contexto, o conceito de Perrenoud é explicitado como a "capacidade de mobilizar diversos recursos cognitivos para enfrentar um tipo de situação" (1999, p. 15).

Em consonância com Andrade (2015), Espindola (2015) promove uma discussão sobre competência entre Perrenoud (2000), Fleury e Fleury (2001), Behar et al. (2013) e Le Boterf (2006), concluindo que esse conceito é dinâmico e deve se adaptar às condições de trabalho em evolução. A autora apropria-se do conceito de competência de Perrenoud (1999), considerando-a como uma capacidade de agir eficazmente em um determinado tipo de situação, apoiada em conhecimentos, mas sem se limitar a eles, ou seja, a composição CHA (Conhecimentos, Habilidades e Atitudes), concepção também utilizada por Gomes (2015) na construção de sua pesquisa sobre professores tutores.

Em seu discurso, Espindola (2015) ainda contextualiza que competência pode ser considerada como "um saber agir responsável e reconhecido que implica mobilizar, integrar e transferir conhecimentos, recursos e habilidades que agreguem valor econômico à organização e valor social ao indivíduo", extraído dos textos de Fleury e Fleury (2001, p. 187), e se sustenta no conceito de Le Boterf das dimensões da competência:

Primeiro, a dimensão dos recursos disponíveis (conhecimentos, saber-fazer, capacidades cognitivas, competências comportamentais...) que ele pode mobilizar para agir; depois, surge a dimensão da ação e dos resultados que ela produz, isto é, a das práticas profissionais e do desempenho. Finalmente, há a dimensão da reflexividade, que é a do distanciamento em relação às duas dimensões anteriores (LE BOTERF, 2006, p. 61 apud ESPINDOLA, 2015, p. 20).

Com tais embasamentos, a autora amplia o conceito de Perrenoud (1999), chegando à composição de competência como o conjunto de um saber-fazer (habilidades), de capacidades cognitivas (que mobilizam os conhecimentos adquiridos), de recursos emocionais (competências comportamentais) e de aptidões sensoriais (atitudes), sendo que o ato reflexivo de suas práticas deve ainda ser levado em consideração. Guimarães (2013) apresenta uma crítica ao conceito de Perrenoud (1999) fundamentada em que há uma contraposição interna no conceito de competência entre a formação tecnicista e a formação crítica de docentes, apontando ainda que o sentido das competências profissionais para professores - e até mesmo na pedagogia das competências - pode ser entendido como a mercantilização da educação, enfocando a formação dos alunos e professores nas necessidades de um sistema capitalista, em que as pessoas são formadas para práticas e fazeres objetivos, perdendo, dessa forma, o caráter crítico e emancipatório. Ela ainda salienta que:

A simples impossibilidade de se poder escolher pela utilização ou não do termo competência e, junto com ele, toda a rede de significados e acepções ideológicas intrínsecas, já evidencia o caráter autoritário da regulamentação da educação no contexto brasileiro (GUIMARÃES, 2013, p. 142).

Apesar de ela sustentar suas críticas em outros trabalhos, afirma que, como o conceito de competência está explicitado nas Diretrizes Curriculares Nacionais para a Formação de Professores da Educação Básica, ele precisa ser respeitado nos programas de formação e capacitação de professores. No entanto, evidencia o fato de que os saberes docentes ainda devem ser valorizados, sendo que atualmente as instituições federais e os órgãos ministeriais valorizam mais a prática do que os saberes e conhecimentos, abordados mais diretamente como conhecimentos teóricos (GUIMARÃES, 2013).

Este mesmo ponto é analisado por Alberto (2015), que destaca que a competência é entendida pelos órgãos ministeriais brasileiros como "a capacidade de mobilizar múltiplos recursos, dentre os quais pontuam os conhecimentos teóricos e experiências da vida profissional e pessoal, para responder às diferentes demandas das situações de trabalho" (ALBERTO, 2015, p. 74). Ele ainda pontua que este conceito é ainda pouco abrangente, tendo em vista as especificidades da ação do professor, e, por esse motivo, opta por não conceituar competência de forma fechada e definida.

A política pública brasileira, nesse sentido, tem acompanhado, mesmo que em atraso, as movimentações mundiais. Segundo Costa (2013), essa discussão de competência na formação de professores intensifica-se a partir dos anos 1960 e 1970, especialmente nos EUA, partindo-se da crença de que alunos com melhor desempenho haviam tido professores mais "eficientes". Nos anos 1980, essa 
discussão entra em ebulição na Europa; no Brasil, é somente a partir dos anos 1990 que a discussão sobre competência toma corpo, porém ainda de forma restrita ao âmbito de qualificação profissional, sendo que $\mathrm{o}$

[...] conceito de competência surgiu para tentar articular a educação com as novas exigências do mercado de trabalho, e uma melhor formação do professor com as características da atualidade. Atualmente, a ideia de competência se refere à renovação da educação, tendo em vista mudanças ocorridas na sociedade, relativas às novas exigências do mundo do trabalho e dos desafios contemporâneos (COSTA, 2013, p. 34).

Em 2001, a partir de um parecer do Conselho Nacional de Educação, a competência surge como núcleo dos cursos de formação de professores, direcionando conteúdos, metodologias e processos avaliativos. A principal crítica de Costa (2013) concerne ao entendimento dos professores sobre os conceitos de competências e habilidades, o que se reflete na criação de currículos baseados em competências. Em geral, professores têm a mesma visão tecnicista e restritiva, e também opressora, abordada nos textos de Guimarães (2013) e Alberto (2015).

Esta visão tecnicista não é a única. Em um âmbito mais sistêmico e holístico, encontramos Fauth et al. (2018) que se baseiam em pesquisas alemãs recentes definindo as competências profissionais docentes como um conjunto de áreas de conhecimento, crenças e variáveis motivacionais que estão ligadas, na prática, ao sucesso vocacional dos professores em termos de qualidade de ensino e ganhos de aprendizado do aluno. Ressaltam ainda que, nas competências profissionais, é importante diferenciar as características pessoais do professor, características didáticas e de ensino na sala de aula e os resultados dos alunos como o produto do ensino deste professor - atentando-se que estes aspectos também são parte da construção da competência e devem ser levados em consideração.

As características pessoais são consideradas como "conhecimento profissional, crenças profissionais sobre ensino e aprendizagem, e motivação para enfrentar os desafios da instrução cotidiana em sala de aula" (FAUTH et al., 2018, p. 1228, tradução nossa). Dentro dessa visão, o conhecimento profissional pode ser entendido também como experiência profissional prática, ou seja, a capacidade de realizar as atividades da própria função. As crenças profissionais são relativas à compreensão de si mesmo (a exemplo de autoeficácia, autopercepção e autoavaliação), enquanto as crenças sobre ensino e aprendizagem se referem ao entendimento do profissional quanto ao modo de promoção ou transmissão do conhecimento de forma direcionada à formação do aluno. Por fim, a motivação do professor referese a variáveis comportamentais, tais como o entusiasmo pelo conteúdo e pelo próprio ensino, aspecto considerado o mais importante.

O conceito de competência para Fauth et al. (2018) pode ser resumido em um conjunto de áreas de conhecimentos técnicos e características pessoais (capacidade prática, crenças e aspectos motivacionais) direcionadas à qualidade de ensino e aos ganhos de aprendizagem dos alunos. Entendemos que, em nossa pesquisa, este é o conceito mais abrangente.

Neste mesmo caminho, Kazu e Demiralp (2016) oferecem uma discussão sobre uma competência do aprendizado ao longo da vida. Essa competência pode ser considerada como um atributo pessoal (GRIFFIOEN, 2018), ou característica pessoal (FAUTH et al., 2018). Por outro lado, Fauth et al. (2018) apresentam conhecimentos e habilidades necessários para que a competência de aprendizado ao longo da vida seja desenvolvida, direcionando-nos a um conceito de competência mais simplificado que envolve o saber e o saber faz̧er. A relevância da discussão desses autores para nossa pesquisa dá-se especialmente quando estes refletem que, para esta competência, existe uma carência de características como "serem curiosos, alfabetizados com a informação, abertos ao aprendizado, com espírito de pesquisa e intrinsecamente motivados" (KAZU; DEMIRALP, 2016, p. 217, tradução nossa). Assim, o que se pode observar é que estas características são aspectos comportamentais e motivadores, oferecendo uma luz à construção do conceito de competência de forma mais sistêmica, e não simplista, como sugerido.

Os componentes motivadores também são abordados por Gutsu et al. (2016), salientando a importância do componente motivacional-axiológico para a construção das competências profissionais dos professores, tendo em vista o cenário de desvalorização social do professor, bem como outros fatores 
relativos à realidade do mercado de trabalho na Rússia. Esses autores consideram ainda que é necessário repensar o conceito, a estrutura, os critérios e os níveis de desenvolvimento da competência profissional do professor de ensino médio, bem como as condições de seu aprimoramento, tendo em vista os desafios modernos, incluindo-se o direcionamento da formação dos alunos por competências.

O conceito motivacional-axiológico foi delineado pelos seguintes componentes, listados em ordem de prioridade, de acordo com pesquisa realizada com professores russos:

$1^{\mathrm{o}}$ - atitude em relação à profissão;

$2^{\mathrm{o}}$ - consciência do significado da profissão;

$3^{\circ}$ - interesse pela disciplina e pelas ciências adjacentes;

$4^{\circ}$ - engajamento na ciência;

$5^{\circ}$ - necessidade de autodesenvolvimento.

Segundo os autores, estes componentes devem fazer parte da construção das competências docentes, da mesma forma como o seu desenvolvimento deve ser levado em consideração para a formação de professores. Tais elementos motivacionais e comportamentais também são encontrados na definição mais adequada para competência docente segundo Elbarbary (2015), que a considera como:

[...] uma abordagem integrada para incluir quatro aspectos como segue: a) conceitual que incluía cognitivo, conhecimento e compreensão; b) aspecto operacional como habilidade funcional, psicomotora e aplicada; c) atitudes; d) meta competência que se preocupa em facilitar a aquisição de outras questões substantivas (DEIST; WINTERTON, 2005 apud ELBARBARY, 2015, p. 83, tradução nossa)

Este conceito carrega um enfoque sistêmico, direcionado às necessidades modernas das competências docentes. Tal construção foi explorada por Elbarbary (2015) em uma pesquisa qualitativa, realizada entre 2013 e 2014 no Egito e na região do Oriente Médio. Os sujeitos definidos para essa pesquisa foram professores atuantes ou em formação de stricto sensu com especialização em e-learning, e o método utilizado foi

[...] a técnica Delphi ${ }^{4}$ com base em dois métodos. O primeiro é o brainstorming através de reuniões informais, onde o painel de especialistas respondeu a perguntas indutivas e dedutivas abertas (McGuire \& Cseh, 2006). O segundo método pediu aos participantes para responderem individualmente a um conteúdo específico em um questionário estruturado (ROSSOUW; HACKER; DEVRIES, 2011 apud ELBARBARY, 2015, p. 84, tradução nossa).

Dessa pesquisa resultou a elaboração de um modelo de competência tecnológica para o corpo docente, segmentado em competências principais, que foram formadas pelos componentes: conhecimentos, habilidades e atitudes (CHA), e metacompetências, consideradas subjacentes ao indivíduo no processo de aprendizado (ELBARBARY, 2015). Esse tipo de segmentação é alinhado com as terminologias de competência-chave, metacompetências e competências transdisciplinares, que são comuns para a construção de matrizes de competência. Marques (2017) oferece uma proposta de classificação desses conceitos, como pode ser visto no Quadro 3, apresentando uma definição objetiva e exemplos práticos que foram pensados no contexto educacional.

Marques (2017) ainda ressalta que as competências transdisciplinares, por sua complexidade, são as que mais têm aderência à área educacional e de formação, sendo que as competências-chave e as metacompetências têm sua importância nos processos avaliativos de pessoas nos âmbitos profissionais

\footnotetext{
4 "É um método que 'busca facilitar e melhorar a tomada de decisões feitas por um grupo de especialistas, sem interação caraa-cara' (Osborne; Collins; Ratcliffe; Millar; Duschl, 2003, p. 697). Normalmente, consiste num conjunto de questionários que são respondidos, de maneira sequencial, individualmente pelos participantes, com informações resumidas sobre as respostas do grupo aos questionários anteriores (OSBORNE et al., 2003), de modo a se estabelecer uma espécie de diálogo entre os participantes e, gradualmente, ir construindo uma resposta coletiva." (MARQUES; FREITAS, 2018, p. 360).
} 
mais genéricos. Esta classificação de competência não é única; porém, em nosso entendimento, ela é didática e fundamentada em outros formatos, como podemos observar na proposta de Costa (2013), que sustenta que a competência é um conjunto de habilidades aplicadas a um certo contexto; e, quando as habilidades são analisadas fora desse contexto pré-determinado ou em outro contexto, elas podem ser consideradas como competências.

Quadro 3 - Classificação das competências em Marques (2017).

\begin{tabular}{|c|c|c|}
\hline Conceito & Definição & Exemplo \\
\hline Competências-Chave & $\begin{array}{l}\text { Adquiridas em contexto de } \\
\text { formação escolar ou profissional } \\
\text { e que podem ser utilizadas ao } \\
\text { longo da vida em diversos } \\
\text { contextos. }\end{array}$ & $\begin{array}{l}\text { Alfabetização; } \\
\text { Solução de Problemas; } \\
\text { Retórica; } \\
\text { Pensamento Crítico. }\end{array}$ \\
\hline Metacompetência & $\begin{array}{l}\text { Conhecimento, entendimento e } \\
\text { compreensão que o indivíduo } \\
\text { tem sobre seus próprios } \\
\text { processos mentais, incluindo o } \\
\text { aprendizado genérico e de novas } \\
\text { competências. }\end{array}$ & $\begin{array}{l}\text { Autoconhecimento; } \\
\text { Conhecimentos Diversos; } \\
\text { Motivação; } \\
\text { Habilidades Volitivas; } \\
\text { Atitudes. }\end{array}$ \\
\hline Competências Transdisciplinares & $\begin{array}{l}\text { Englobam as competências de } \\
\text { domínio geral, metacognitivas, de } \\
\text { atitudes motivacionais e as } \\
\text { competências direcionadas às } \\
\text { habilidades volitivas. São } \\
\text { direcionadas para a ação, uma vez } \\
\text { que combinam elementos } \\
\text { cognitivos, motivacionais e } \\
\text { sociais para compor o seu } \\
\text { conjunto. }\end{array}$ & $\begin{array}{l}\text { Experimentação, representação } \\
\text { gráfica, interpretação de dados } \\
\text { e de texto; } \\
\text { Planejamento de estratégias de } \\
\text { ação, avaliação dos seus próprios } \\
\text { resultados, técnicas de } \\
\text { aprendizagem auto-organizadas; } \\
\text { Autoconceito positivo, interesse } \\
\text { em aprender, tolerância para } \\
\text { informações contraditórias à sua } \\
\text { opinião; } \\
\text { Hábitos de trabalho, habilidades } \\
\text { de concentração, orientação de } \\
\text { ação. }\end{array}$ \\
\hline
\end{tabular}

Fonte: Elaborado pelos autores com base em Marques (2017, p. 99-101).

Podemos considerar que Costa (2013) enxerga competência como uma habilidade ampla, enquanto a habilidade é uma competência específica. Para ele, uma habilidade pode fazer parte de diversas competências, e a mobilização de conhecimentos deve vir em face da diversidade, acolhendo diferenças e utilizando-as nas situações de ensino-aprendizagem para melhores resultados, sendo também necessárias, para isso, a mobilização de valores e as decisões para agir de modo pertinente em determinada situação.

Costa (2013, p. 40) apresenta uma proposta de classificação de competências, aproximandoas das dez famílias de competências para ensinar sugeridas por Perrenoud em 1999, a saber:

- organizar e dirigir situações de aprendizagem;

- administrar a progressão das aprendizagens;

- conceber e fazer evoluir os dispositivos de diferenciação;

- envolver os alunos em suas aprendizagens e em seu trabalho;

- trabalhar em equipe;

- participar da administração da escola;

- informar e envolver os pais;

- utilizar novas tecnologias; 
- enfrentar os deveres e os dilemas éticos da profissão;

- administrar sua própria formação contínua.

A proposta de Costa (2013) oferece oito famílias de competências e as relações de domínio, aptidões, conhecimentos e outras habilidades observadas no Quadro 4.

Quadro 4 - Classificação de competências proposta por Costa (2013).

\begin{tabular}{|c|c|}
\hline Competência & Definição \\
\hline Técnicas & $\begin{array}{l}\text { Relacionadas ao domínio de } \\
\text { especialidades. }\end{array}$ \\
\hline Intelectuais & Relacionadas às aptidões mentais. \\
\hline Cognitivas & $\begin{array}{l}\text { Relacionadas ao intelectual e ao domínio } \\
\text { de conhecimento. }\end{array}$ \\
\hline Relacionais & Relacionadas às relações interpessoais. \\
\hline Sociais e Políticas & Relacionadas à participação social. \\
\hline Metodológicas & $\begin{array}{l}\text { Relacionadas às organizações de } \\
\text { atividades. }\end{array}$ \\
\hline Liderança & $\begin{array}{l}\text { Relacionada à capacidade de influenciar } \\
\text { pessoas para fins profissionais. }\end{array}$ \\
\hline Empresariais e Organizacionais & Aplicadas à Organização e Gestão. \\
\hline
\end{tabular}

Fonte: Elaborado pelos autores com base na classificação de Costa (2013, p. 39-40).

Pode-se observar que essas classificações são mais genéricas que as propostas por Marques (2017) e que, apesar de serem direcionadas às competências docentes, se aproximam mais do conceito de saberes. Outra abordagem de proposta classificativa pode ser encontrada em Bandeira e Souza (2014), que se apoiam em Zarifian $(2003,2009,2011)$ quando este afirma que:

[...] entende a competência como a faculdade de mobilizar redes de atores em volta de situações, compartilhando desafios e assumindo responsabilidades. Tal assunção de responsabilidades baseia-se na capacidade de tomar iniciativa e responsabilizar-se em situações profissionais com as quais o indivíduo se defronta por meio de uma inteligência da prática que se apoia em conhecimentos adquiridos (BANDEIRA; SOUZA, 2014, p. 274).

Os autores defendem a importância dos estudos de competências direcionadas aos professores e salienta que, apesar de termos autores que já classificam as competências docentes, tais como Perrenoud (2000) e, no Brasil especificamente, Kuenzer (2000, 2003), a classificação proposta por Zarifian é mais aderente à análise proposta, tendo em vista que Kuenzer aprofunda as competências por meio da prática educativa como uma unidade teórico-prática e unitária, excluindo espaços e tarefas desses processos. Perrenoud, por seu turno, enfoca um caráter muito mais cognitivo, enquanto a proposta de Zarifian se interessa pelo processo de mobilização direcionada à atividade profissional de forma concreta, como se pode ver no Quadro 5.

Quadro 5 - Classificação de competências em Bandeira e Souza (2014).

\begin{tabular}{|c|l|}
\hline Competência & \multicolumn{1}{|c|}{ Definição } \\
\hline Processos & $\begin{array}{l}\text { Conhecimentos sobre processos do trabalho, capacidade } \\
\text { de estruturar processos, incluindo apropriação de } \\
\text { inovações e tecnologia. }\end{array}$ \\
\hline Técnica & $\begin{array}{l}\text { Diz respeito a conhecimentos específicos sobre o trabalho } \\
\text { a ser realizado e com a capacidade de entrega de um } \\
\text { produto ou serviço. }\end{array}$ \\
\hline Organização & $\begin{array}{l}\text { Parte do princípio de autonomia. Requer conhecimentos } \\
\text { do funcionamento da organização e a capacidade de } \\
\text { distribuir recursos adequadamente, organizando fluxos } \\
\text { além do funcionamento, sendo possível redefinir estas } \\
\text { questões. }\end{array}$ \\
\hline Serviço & \begin{tabular}{l} 
Prevê o conhecimento da própria atividade e seu fim \\
\hline
\end{tabular} \\
\hline
\end{tabular}




\begin{tabular}{|l|l|}
\hline & $\begin{array}{l}\text { (produto ou serviço) para antever impactos diretos e } \\
\text { indiretos aos destinatários-fim. }\end{array}$ \\
\hline Competências Sociais & $\begin{array}{l}\text { São as atitudes que sustentam os comportamentos das } \\
\text { pessoas em três campos: autonomia, tomada de } \\
\text { responsabilidade e comunicação. Estão relacionadas com } \\
\text { a capacidade de (criar) manter relacionamento em seu } \\
\text { entorno. }\end{array}$ \\
\hline
\end{tabular}

Fonte: Elaborado pelos autores com base em Bandeira e Souza (2014, p. 274-275).

Esta classificação é muito similar à proposta por Costa (2013), embora exclua os aspectos políticos e reúna os demais domínios em cinco agrupamentos. Ambos os modelos oferecem classificações genéricas, sendo que a mesma classificação poderia ser utilizada para qualquer profissão. Porém, as propostas de Bandeira e Souza (2014) e Costa (2013) apresentam um viés mais politizado, orientado para o trabalho de forma bem tecnicista e contextualizado, ao passo que a proposta de Marques (2017) oferece uma visão mais subjetiva, proporcionando uma maior valorização de conhecimentos específicos e aspectos motivacionais e comportamentais.

Corroborando com esta visão de complexidade, Cassundé et al. (2017) revisitam o termo "competência para a ação":

Baseado em Dejoux (1996), Weinert (1999) e Euler e Hahn (2004), Adelsberger, Ehlers e Schneckenberg (2008) e Schneckenberg (2010b) definem competência para ação como a combinação de componentes cognitivos e motivacionais em um sistema holístico de conhecimentos, habilidades e atitudes. Ou seja, competência para ação está relacionada com a capacidade de agir dentro de um determinado contexto de uma maneira responsável e adequada, integrando conhecimento complexo, habilidades e atitudes, complementam os autores, referindo-se à definição proposta por Van der Blij (2002) (CASSUNDÉ et al., 2017, p. 473).

Os autores conseguem, dessa forma, oferecer uma definição ampla para o termo, unificando Teorias Psicológicas, da Ação e Sociológicas em um único contexto, trazendo com clareza os componentes da competência: Disposições Individuais (Habilidades, Aptidão, Motivação e Valores), Contextos (que podem ser complexos, não definidos ou dinâmicos) e Normas Consensuais (Adequação e Responsabilidade), que determinam os padrões do comportamento adequado. Esta estrutura inicial desdobra-se em seis blocos de componentes da competência para ação: aprendizagem, sistema de disposições (que inclui conhecimentos, habilidades e atitudes), motivação, desempenho, contexto e competências essenciais (CASSUNDÉ et al., 2017).

Esses autores trazem ainda o conceito de competência docente de Tigellar et al. (2004, p. 255, apud CASSUNDÉ et al., 2017), que a define como "um conjunto integrado de características pessoais, conhecimentos, habilidades e atitudes, que são necessários para a efetiva performance em variados contextos de ensino". À luz dessas duas teorizações, eles oferecem um modelo de classificação para a competência para ação docente, direcionando o descritivo para a prática da profissão, apresentado no Quadro 10, de tal forma que abraça o direcionamento prático, pedagógico e de saberes docentes. Fica evidente que este modelo deixa de lado as características da criticidade, o que nos parece ser uma opção proposital, pois, diferentemente de uma discussão intelectual, filosófica ou teórica sobre o tema, eles a direcionam para a ação, e nem sempre os estudos teórico-filosóficos têm este fim. Segundo os autores, essas competências ainda podem ser integradas em conjuntos dentro de processos de desempenho individual, criando famílias de competências.

Quadro 6 - Classificação das competências docentes em Cassundé et al. (2017).

\begin{tabular}{|r|l|}
\hline Competência & Descritivo \\
\hline Específico & $\begin{array}{l}\text { Solução de problemas na área tema; } \\
\text { Conhecimento qualificado; } \\
\text { Conhecimento valorizado. }\end{array}$ \\
\hline Metodológica & $\begin{array}{l}\text { Planejamento criativo de métodos em tarefas e soluções; } \\
\text { Aplicação eficiente de métodos em tarefas e soluções; } \\
\text { Estruturação eficiente de procedimentos cognitivos. }\end{array}$ \\
\hline Social & Comunicação, cooperação e interação eficiente dentro do grupo; \\
\hline
\end{tabular}




\begin{tabular}{|l|l|}
\hline & Comportamento adequado de acordo com as orientações coletivas. \\
\hline Pessoal & Autoavaliação crítica; \\
& Desenvolvimento de atitudes, orientação para valores, motivos e autopercepção produtivos e \\
& positivos; \\
& Revelar talento pessoal, motivação e ambição; \\
& Aprender a desenvolver-se dentro e além do contexto de trabalho. \\
\hline
\end{tabular}

Fonte: Adaptado de Cassundé et al. (2017, p. 476).

As classificações de competência são importantes para a discussão do conceito, bem como para a discussão sobre a profissionalidade docente e das possibilidades de interpretação, pois servem como embasamento para a construção de um conceito cada vez mais amplo, que atenda às necessidades e aos anseios dos professores. A discussão sobre competência, apesar de já ser considerada por alguns como ultrapassada, ainda está longe de ser extinta. Como pudemos observar, muitos são os aspectos criticados, especialmente por posicionamentos políticos e epistemológicos; por outro lado, também são muitos os direcionamentos práticos e as justificativas do mundo contemporâneo para se utilizar o formato de competência.

Entendemos, porém, que um conceito, para servir de base e eixo estruturador de nossa pesquisa, deve ser elaborado de forma ampla, que respeite as reais especificidades da profissão, as diversidades de pensamentos e correntes e que abrace a singularidade do processo de ensinar e aprender. Fazer apenas uma síntese subjetiva é raso, sendo que instrumentos diferenciados podem nortear de forma mais ampla a construção final do texto. Por esse motivo, antes de concluir sobre o conceito, faremos uma análise do Corpus Textual.

\section{Análise de Corpus Textual}

Para a análise de Corpus Textual ${ }^{5}$, lançamos mão do sistema Iramuteq, que "é um software licenciado por GNU GPL (v2) ${ }^{6}$ que permite fazer análises estatísticas sobre corpus textuais e sobre Quadros indivíduos/palavras" (CAMARGO; JUSTO, 2014, p.1). É um software livre, gratuito e de fácil utilização, tendo em vista a possibilidade de alternar a linguagem da interface para português; ele não traz tantas possibilidades quanto outros softwares de análise textual (RATINAUD, 2014), porém, pela simplicidade de análise exigida neste momento de pesquisas, ele se mostrou adequado.

Optamos pela análise de constructos e suas frequências nos conceitos apresentados pelos autores, buscando similaridades nos textos. A análise realizada pelo sistema baseia-se em uma Análise Lexical e na Classificação Hierárquica Descendente (CHD), em que os constructos são

[...] classificados em função dos seus respectivos vocabulários, e o conjunto deles é repartido em função da frequência das formas reduzidas. A partir de matrizes cruzando segmentos de textos e palavras (em repetidos testes do tipo X2), aplica-se o método de CHD e obtém-se uma classificação estável e definitiva (CAMARGO; JUSTO, 2014, p. 5).

O sistema trabalha automaticamente, analisando as estruturas de forma estatística, sendo o produto dessa análise um Dendograma da Classificação Hierárquica Descendente dos textos, que ilustra as relações entre as classes e os vocábulos pertencentes a cada classe. Para nossa análise, foram criadas seis classes de vocábulos, relacionadas entre si, sendo que inicialmente o texto foi segmentado em duas correlações distintas e, em seguida, ramificado mais vezes para a construção de classes aderentes, conforme mostra a Figura 2.

Figura 2 - Dendograma de textos extraídos da RSL.

\footnotetext{
${ }^{5} \mathrm{O}$ corpus é construído pelo pesquisador. É o conjunto de texto que se pretende analisar e é definido pelo caráter da pesquisa. ${ }^{6}$ GNU GLP versão 2 é uma licença de software livre que se destina a garantir a liberdade de compartilhar e alterar um software, garantindo que ele seja gratuito para todos os seus usuários (GNU, 1991). Foi substituída por nova versão em 2007. 


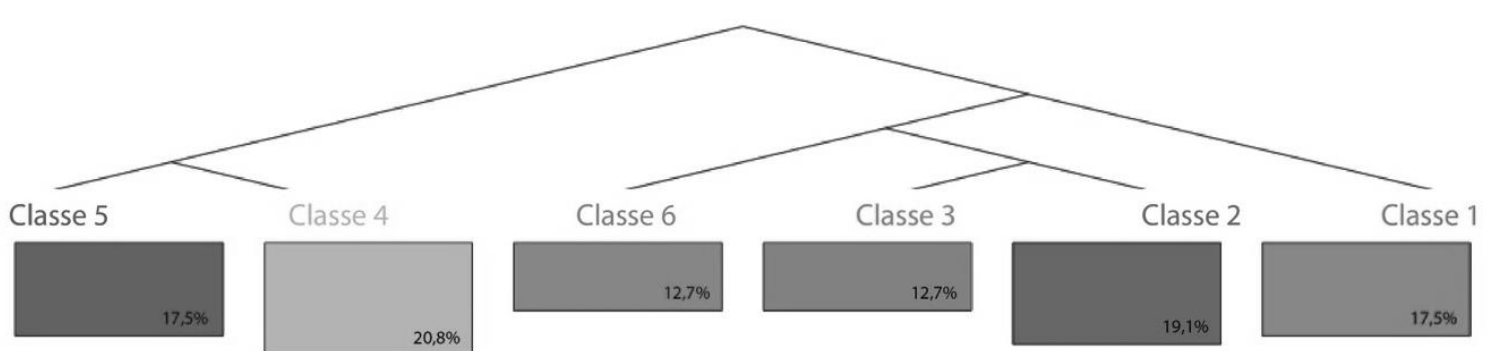

\begin{tabular}{|c|c|c|}
\hline $\begin{array}{l}\text { formação } \\
\text { dever } \\
\text { didático } \\
\text { científico } \\
\text { consideração } \\
\text { pedagógico } \\
\text { levar } \\
\text { prático } \\
\text { diverso } \\
\text { professor } \\
\text { desenvolvimento } \\
\text { ensinar } \\
\text { docente } \\
\text { agir } \\
\text { explicar } \\
\text { exemplo } \\
\text { respeito } \\
\text { construção } \\
\text { utilizar } \\
\text { pesquisador } \\
\text { domínio } \\
\text { curricular } \\
\text { conteúdo }\end{array}$ & $\begin{array}{l}\text { aluno } \\
\text { docente } \\
\text { ensino } \\
\text { característica } \\
\text { aprendizagem } \\
\text { sala } \\
\text { aula } \\
\text { professor } \\
\text { ensinar } \\
\text { disciplina } \\
\text { especifico } \\
\text { área } \\
\text { pedagógico } \\
\text { aspecto } \\
\text { histórico } \\
\text { aprender } \\
\text { respeito } \\
\text { relacionar } \\
\text { dominar } \\
\text { pesquisador } \\
\text { geral } \\
\text { curricular } \\
\text { conteúdo } \\
\text { organizacão }\end{array}$ & $\begin{array}{l}\text { determinado } \\
\text { responsável } \\
\text { agir } \\
\text { autor } \\
\text { prático } \\
\text { integrar } \\
\text { individuo } \\
\text { capacidade } \\
\text { contexto } \\
\text { considerar } \\
\text { próprio } \\
\text { amplo } \\
\text { competente } \\
\text { precisar } \\
\text { relacionar } \\
\text { faculdade } \\
\text { dominar } \\
\text { geral } \\
\text { atividade } \\
\text { mesmo } \\
\text { diferente }\end{array}$ \\
\hline
\end{tabular}

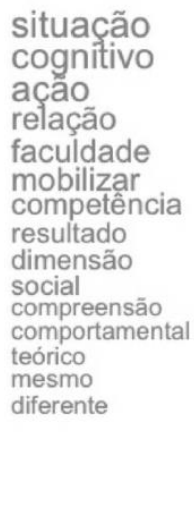

aptidão

conceito capacidade recurso comportamental considerar mobilizar experiência competente conhecimento pessoal abordagem cognitivo dimensão indivíduo habilidade necessário atitude tarefa performance desempenho distinguir conjunto integrar contexto conhecin
valor atividade abordagem resultado especifico aspecto proprio histórico explicar exemplo aprende amplo

Fonte: Desenvolvido pelos autores com o software Iramuteq.

A análise do dendograma resultante é rica, pois considera a frequência e a correlação dos vocábulos nos textos e, consequentemente, sua importância no contexto. A frequência é representada pelo tamanho da fonte na construção da imagem, e a correlação, pelas linhas e sequência em que se apresentam (CAMARGO; JUSTO, 2014). Tendo em vista que todos os textos inclusos foram relativos ao conceito de competência docente, podemos ter uma imagem interessante dos principais termos utilizados.

As Classes 4 e 5 fazem parte de uma primeira divisão do texto e dizem respeito às contextualizações, aos ambientes e à finalidade da competência, fato este que podemos observar pelas palavras em destaque: "formação", “dever", "didático", "pedagógico", “aluno", "ensino”, "característica" e "aprendizagem" - palavras muito presentes nos discursos de contextualização e nos conceitos que direcionam a atividade profissional docente. As Classes 1, 23 e 6 têm uma abordagem mais direcionada à competência propriamente dita; em cada uma dessas classes, apresentam-se vocábulos importantes à construção conceitual de competência.

Quando observamos a Classe 1, chamamos a atenção para as palavras "habilidade", "atitude" e "tarefa"; conforme pudemos perceber nas discussões anteriores, algumas propostas de conceito direcionam as mobilizações de atributos de competência para a realização de tarefas específicas (URZEDO, 2017; ELBARBARY, 2015; MARQUES, 2017); as habilidades são consideradas o saberfazer e estão intrinsecamente conectadas às atitudes, até mesmo pelo fato de a construção do conceito mais difundido atrelar essas duas concepções como conhecimento, que também é apresentado nessa mesma classe, porém, com menor destaque (CASSUNDÉ, 2017; MARQUES, 2017; KIM et al., 2018). O menor destaque do conhecimento parece corroborar com a ideia de que os saberes têm obtido menor valorização por parte das conceitualizações, tal como apontado por Guimarães (2013). Concluímos que nesta classe estão os vocábulos centrais interconectados com o conceito de competência.

Pela análise da Classe 2, sugerimos atentar aos substantivos "Aptidão", "Capacidade", "Recurso", "Comportamental", "Experiência" e, mais uma vez, "Conhecimento", com maior relevância que na Classe 1. Como verbo, vale ressaltar "Mobilizar", que inclusive se repetirá na Classe 3, desconsiderando o verbo "considerar", que foi utilizado como auxiliar nas frases analisadas. A capacidade 
de mobilização parece-nos ser o centro do conceito de competência, como podemos observar nos segmentos de texto:

[...] Conceito de Perrenoud considerado é a capacidade de mobilizar diversos recursos cognitivos para enfrentar um tipo de situações[...] (ANDRADE, 2015, p. 62, grifo nosso).

[...] as capacidades cognitivas são o que mobilizam os conhecimentos os recursos emocionais as competências comportamentais e as aptidões sensoriais nos parecem ser as atitudes (ESPINDOLA, 2015, p. 20, grifo nosso).

[...] capacidade de mobilizar múltiplos recursos dentre os quais pontuam os conhecimentos teóricos e experiências da vida profissional e pessoal para responder às diferentes demandas das situações de trabalho [...] (ALBERTO, 2015, p. 70, grifo nosso).

Além disso, o aspecto comportamental é algo presente em diversas concepções de competência ou nas suas classificações, mesmo quando não aparece expressamente como comportamento; entretanto, podemos identificá-lo como motivação, hábitos, responsabilidade e até mesmo saber-ser (ESPINDOLA, 2015; MEDEIROS, 2016; MARQUES, 2017).

A análise da Classe 3 traz os vocábulos de destaque como "Situação", "Cognitivo", "Ação", "Relação" e, mais uma vez, o verbo "Mobilizar". Em consonância com a Classe 1, a realização de tarefas nada mais é que uma ação. O trabalho é uma ação situacional. A mobilização de recursos cognitivos para uma ação situação por si já poderia ser um conceito de competência; porém, para a competência docente, a relação e a interação social são relevantes. A prática docente prevê relações sociais, competências e habilidades sociais (MEDEIROS, 2016; MARQUES, 2017).

A Classe 6 apresenta como a principal palavra "determinado" - em geral, este vocábulo é utilizado como palavra acessória nas construções, não sendo o adjetivo de determinação. Dessa forma, queremos chamar a atenção para as palavras "Responsável", "Agir", "Prático", "Integrar", "Indivíduo" e "Capacidade". O verbo "Integrar" tem uma relevância no contexto da construção desse conceito, especialmente quando entendemos a importância não apenas de mobilizar os recursos cognitivos, mas também de integrar os diversos recursos individuais: esta capacidade integrativa reflete-se na ação individual e nas relações sociais e de trabalho. Em tese, mobilizar significa colocar para a ação, enquanto integrar é a inclusão de algo ou de si mesmo em um conjunto, formando um todo maior e mais coerente. Estes dois verbos, juntos, podem nos ajudar na concepção de competência.

Após elencarmos as principais palavras do dendograma, voltamos ao sistema Iramuteq para que, por meio de uma análise fatorial dos vocábulos selecionados, fosse possível uma representação gráfica das importâncias e relações entre os termos, baseando-nos nos instrumentos utilizados (Figura $3)$.

A Figura 3 traz riqueza interpretativa no que tange à importância do conhecimento para as competências. A crítica às competências docentes é vasta e direcionada, especialmente por não se valorizarem os saberes docentes.

A compreensão de saberes docentes é muito mais ampla do que os conhecimentos, correspondendo também ao saber-fazer e saber-ser (OLIVEIRA, F. 2017), mas sempre está imbricada ao conhecimento e à experiência do professor. Em nossa representação gráfica, a competência tem valor semelhante ao conhecimento, sendo conectada diretamente a ele, e dele derivam os demais vocábulos. Em analogia, podemos compreender que o conhecimento, quando observado pelo viés do saber teórico, conhecimento técnico e informações, é base para a construção da competência e o meio para o desenvolvimento de outros recursos cognitivos. 
Figura 3 - Representação gráfica de importância e inter-relações.

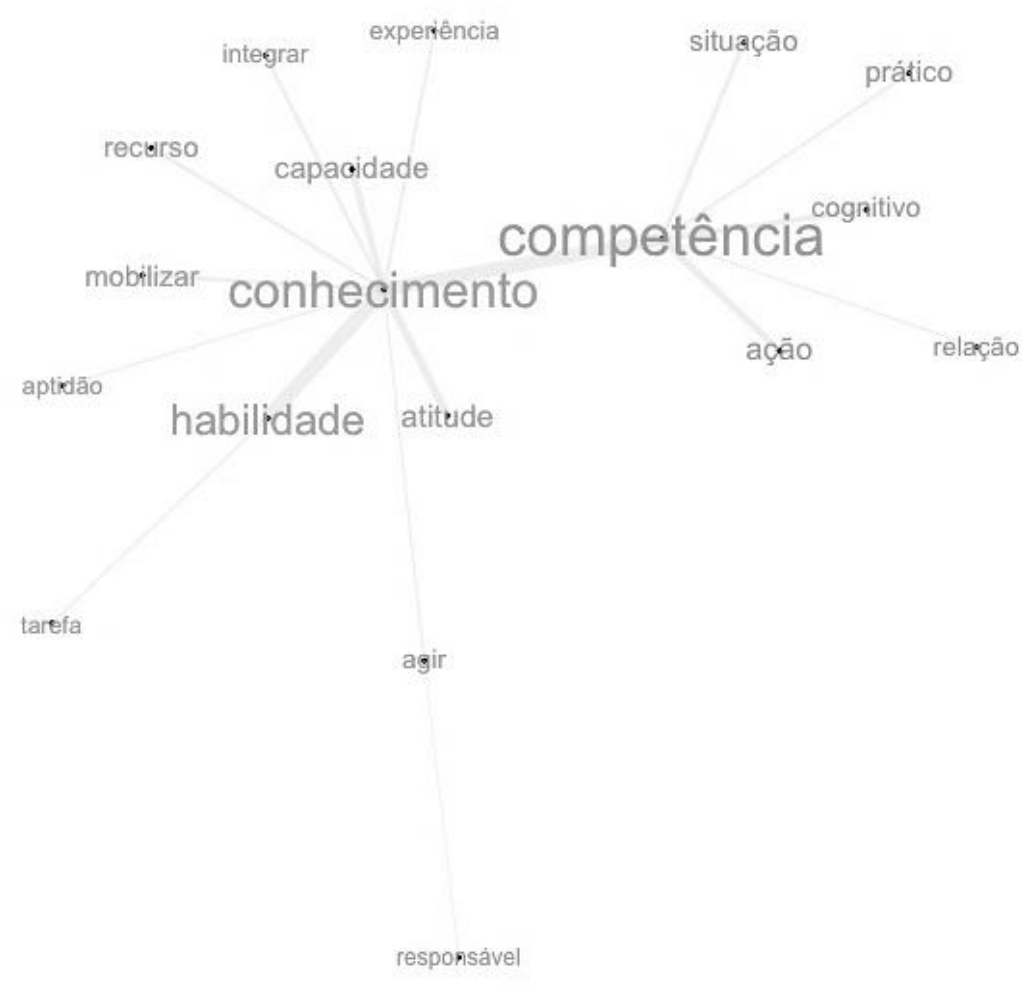

Fonte: Desenvolvido pelos autores com o software Iramuteq.

Seguindo na mesma lógica analógica, podemos inferir que a competência é o meio para o desenvolvimento de situações e para a ação e a prática, bem como um meio para outros aspectos cognitivos. Entendemos que estes vocábulos são os elementos que devem constar em nosso conceito de competência, que surgem e são sustentados pela discussão promovida pela Revisão Sistemática de Literatura e são suportados por uma técnica fatorial estatística, oferecida pelo próprio sistema Iramuteq, que busca as principais conexões semânticas, suas relevâncias por quantidade de aparições, bem como proximidades textuais.

\section{CONSIDERAÇÕES FINAIS}

A análise dos documentos obtidos por RSL demonstra que o tema competência docente merece discussões permanentes, tendo em vista tanto o caráter dinâmico do termo, como o caráter complexo e dinâmico da profissão docente. Durante o processo de RSL, foram observados diversos olhares sobre as competências docentes, e os autores discutem tanto as questões terminológicas, como sua aplicabilidade e possibilidades de evolução.

Dentro de nossa pesquisa, acreditamos na possibilidade da consolidação de um conceito mais democrático e abrangente, utilizando a análise crítica realizada e as análises quantitativas, que nos deram os principais termos que devem compor o conceito.

Por esse aspecto, em nossas considerações finais, propomos a construção do conceito de competência docente, consolidado e reconstruído, como a capacidade individual de mobilizar e integrar recursos cognitivos como conhecimentos, habilidades, aspectos comportamentais (atitudes, valores e crenças) e relacionais (participação, interação e experiência), com o objetivo de um agir responsável direcionado à situação de ensino e aprendizagem e às atividades envolvidas neste processo.

Esse conceito resultante não é carregado de ineditismo, mas tem como objetivo buscar um contexto mais democrático do termo, bem como valorizar os principais aspectos criticados nas diversas instâncias. Vale ressaltar que a evolução do conceito de competência docente vem apresentando um caráter dinâmico, e, por esse motivo, consolidar um conceito único e estagnado é negligenciar as 
transformações sociais e de trabalho ao qual ele se refere. Além disso, as duras críticas no que tange à utilização do conceito de competência docente, contribuindo para o achatamento da profissionalidade docente, devem ser lembradas e consideradas; porém, mesmo em meio às críticas, este conceito faz-se necessário como base para a construção dessa mesma profissionalidade.

Como preceito em RSL, é importante retomarmos o conceito-controle que oferece uma base comparativa de onde iniciamos a discussão e até onde chegamos. O nosso conceito-controle é: "conjunto de conhecimentos, habilidades e atitudes (isto é, conjunto de capacidades humanas) que justificam um alto desempenho" (FLEURY; FLEURY, 2001). Ao comparar ambas as construções, podemos identificar que o conceito construído traz um melhor direcionamento à profissão docente e às suas especificidades, além de ampliar a estrutura englobando aspectos sociais e comportamentais e incluir o aspecto de agir responsável, que, em nosso entendimento, carrega muito do espírito crítico necessário para a profissão docente.

Conseguimos responder às questões de pesquisa da RSL de forma satisfatória. Quanto aos conceitos encontrados, pudemos observar muitas construções diferenciadas. No entanto, em sua maioria, reforçam a importância dos conhecimentos teóricos, dos conhecimentos aplicados (quer como ações, habilidades ou experiências), dos comportamentos ou atitudes, vinculados de alguma forma ao ambiente em que se está inserido, o que nos faz observar a importância de termos um conceito de competência docente específico, pois o ambiente escolar tem peculiaridades e dinâmicas diferenciadas de qualquer outro ambiente profissional. Vale apontar nestas considerações finais que esta pesquisa foi desenvolvida como parte do Desenvolvimento de uma Matriz de Competências Docentes em Tecnologias Digitais, fruto de dissertação de mestrado, utilizando este conceito reconstruído como fio condutor. Por esta razão, respeitar as especificidades profissionais dos professores tornou-se ainda mais importante, oferecendo uma proposta de conceito mais abrangente e sistêmico.

\section{REFERÊNCIAS}

ALBERTO, Dirceu Luiz. Competências na Formação Docente: Um Olhar Hermenêutico. 138 f. Tese (Doutorado em Educação). Santa Maria: Universidade Federal de Santa Maria, 2015.

ANDRADE, Rogério Alencar Ferraz de. As Competências Docentes Enunciadas pelos Professores de Lingua Materna. 2015. 124f. Tese (Doutorado em Letras) (UCS/UNIRITTER). Porto Alegre: Universidade de Caxias do Sul, Centro Universitário Ritter Dos Reis, 2015.

BANDEIRA, Yonara Miranda; SOUZA, Paulo César Zambroni de. Mobilização de Competências na Profissão Docente: contribuições do modelo da competência. Psicologia Escolar Educacional, v. 18 n. 2, p. 273-281, ago. 2014.

BEHAR, Patricia Alejandra (org.). Competências em Educação a Distância. Porto Alegre: Penso, 2013. Recurso Eletrônico.

BRASIL. Ministério da Educação. Base Nacional Comum Curricular. Brasília, 2017. Disponível em: http://basenacionalcomum.mec.gov.br/images/BNC C_20dez_site.pdf. Acesso em: 02 dez. 2019.

BRASIL. Ministério da Educação. Conselho Nacional da Educação. Parecer de 19 de setembro 2019. Diretrizes Curriculares Nacionais e Base Nacional Comum para a Formação Inicial e Continuada de Professores da Educação Básica. $3^{a}$ versão. Brasília, 18 set. 2019.

BRIZOLA, Jairo; FANTIN, Nadia. Revisão de Literatura e Revisão Sistemática de Literatura. Revista de Educação Vale dos Arinos, Juara, v. 3, n. 2, p. 23-39, jul./dez. 2016. 
CAMARGO, Brigido Vizeu; JUSTO, Ana Maria. Tutorial para Utilização do Software IRaMuTeQ: R Interface para Análises Multidimensionais de Textos e Questionários. Florianópolis: Laboratório de Psicologia Social da Comunicação e Cognição - UFSC - Brasil, 2014. Disponível em: http://www.iramuteq.org/documentation/fichiers/Tutorial\%20IRaMuTeQ\%20em\%20portugues_17. 03.2016.pdf. Acesso em: 02 nov. 2018.

CASSUNDÉ, Fernanda Roda de Souza Araújo; MENDONZA, José Ricardo Costa de; BARBOSA, Milka Alves Correia. A influência das condições institucionais no desenvolvimento de competências eletrônicas dos professores para o ensino na EAD: proposição de um modelo analítico. Revista Avaliação, Campinas, v. 22 n. 2, ago. 2017.

CONCEIÇÃO, Cristina; SOUSA, Óscar de. Ser professor hoje: O que pensam os professores das suas competências. Revista Lusófona de Educação, n. 20, p. 81-98, 2012.

COSTA, Angelo Brandeli; ZOLTOWSKI, Ana Paula Couto. Como Escrever um Artigo de Revisão Sistemática In: Koller, Silvia H.; Couto, Maria Clara P. de Paula; Hohendorff, JeanVon (Orgs). Métodos de pesquisa: manual de produção científica. Porto Alegre: Penso, 2014.

COSTA, Patricia Rodrigues. A Formação de Tradutores em Instituições de Educação Superior Públicas Brasileiras: Uma Análise Documental. 2018. 450 f. Tese (Doutorado em Estudos da Tradução). Florianópolis: Universidade Federal de Santa Catarina, 2018.

COSTA, Rodrigo Tadeu Pereira da. Competências e Habilidades na Formação Inicial do Futuro Professor: Uma Análise de Projetos Pedagógicos de Cursos de Licenciatura Em Matemática. 2013. 133 f. Dissertação (Mestrado em Educação Matemática). Campo Grande: Fundação Universidade Federal de Mato Grosso Do Sul, 2013.

DAM, M.; JANSSEN, F. J. J. M.; DRIEL, J. H. Van. Attention to Intentions: How to Stimulate Strong Intentions to Change. Research in Science Education, New Zealand, v. 48, n. 2, p. 369-387, abr. 2018. Disponível em: https://link.springer.com/article/10.1007\%2Fs11165-016-9572-4. Acesso em: 30 out. 2018.

DUTRA, Joel Souza. Gestão por competências: um modelo avançado para o gerenciamento de pessoas. São Paulo: Editora Gente, 2001.

ELBARBARY, Rafik Said. Identifying Core Mobile Learning Faculty Competencies Based Integrated Approach: A Delphi Study. Journal of Education and Learning, Egypt, v. 4, n. 2, p. 81-95, jan. 2015. Disponível em: http://eric.ed.gov/?id=EJ1075152. Acesso em: 30 out. 2018.

ESPINDOLA, Joice de. Percep̧cão Docente Sobre os Indicadores de Competência Digital. 2015. 108 f. Dissertação (Mestrado em Educação Matemática e Tecnológica). Recife: Universidade Federal de Pernambuco, 2015.

FAUTH, Benjamin; DECRISTAN, Jasmin; RIESER, Svenja; KLIEME, Eckhard; BÜTTNER, Gerhard. Autonomous Motivation in the Indonesian Classroom: associations with teacher characteristics and student outcomes in primary school. Social Psychology of Education, p. 1-25, jun. 2018. Disponível em: http://link.springer.com/article/10.1007/s11218-018-9462-x. Acesso em: 30 out. 2019.

FLEURY, Maria Tereza Leme; FLEURY, Afonso. Construindo o conceito de competência. Revista Administração Contemporânea, Curitiba, v. 5, n. edição especial, p. 183-196, 2001. Disponível em: 
http://www.scielo.br/scielo.php?script=sci_arttext\&pid=S1415-

65552001000500010\&lng=en\&nrm=iso. Acesso em: 25 set. 2017.

GOMES, Ednaldo Farias. A Profissionalidade do Tutor Online na Docência no Sistema Universidade Aberta do Brasil: tensões entre concepções e exercício docente. 2015. 199 f. Tese (Doutorado em Educação). Recife: Universidade Federal de Pernambuco, 2015.

GONÇALVEZ, Wesley Antonio; CORRÊA, Dalila Alves; BERTASSO, André Luís; RIBEIRO, Gabriela Garcia; ANDRADE, Willian Machado; SOUZA, Rívia Dornelas de. Confrontando o Conceito de Competências pela sua Diversidade e Aplicação: Um Olhar entre a Teoria e a Prática. In: CONVIBRA, 2016. XIII Congresso Online - Administração, 2016. v. XIII. Disponível em: http://www.convibra.com.br/upload/paper/2016/34/2016_34_12725.pdf. Acesso em: 02 set. 2018.

GORZONI, Sílvia De Paula; DAVIS, Claudia. O conceito de profissionalidade docente nos estudos mais recentes. Cadernos de Pesquisa, São Paulo, v. 47, n. 166, p. 1396-1413, dez. 2017. Disponível em: http://www.scielo.br/scielo.php?script=sci_arttext\&pid=S0100-

15742017000401396\&lng=pt\&nrm=iso. Acesso em: 06 nov. 2018.

GRIFFIOEN, Didi. Building Research Capacity in New Universities During Times of Academic Drift: Lecturers Professional Profiles. Higher Education Policy, London, p. 1-20, maio 2018. Disponível em: https://link.springer.com/article/10.1057\%2Fs41307-018-0091-y. Acesso em: 30 out. 2019.

GUIMARÃES, Julia de Moura Martins. Formação docente em tempos de crise ambiental: problematizações epistemológicas. 2013. 183 f. Dissertação (Mestrado Profissional em Educação). Lavras: Universidade Federal de Lavras, 2013.

GUTSU, Elena G. et al. Studying Motivational-Axiological Component of Professional Competence of a College Teacher. International Journal of Environmental and Science Education, Rússia, v. 11, n. 18, p. 1265012657, jan. 2016. Disponível em: http://eric.ed.gov/?id=EJ1124631. Acesso em: 30 out. 2018.

HABERMAS, Jüngen. Consciência Moral e Agir Comunicativo. $1^{\text {a }}$ ed. Rio de Janeiro: Tempo Brasileiro, v. 1, 1989.

HIPÓLITO, José Antônio Monteiro. A gestão da administração salarial em ambientes competitivos: análise de uma metodologia para construção de sistemas de remuneração por competências. São Paulo, 2000. Dissertação (Mestrado em Economia). São Paulo: Universidade de São Paulo, 2000.

KAZU, Hilal; DEMIRALP, Demet. Faculty Membros' Views on the Effectiveness of Teacher Training Programs to Upskill Life-Long Learning Competence. Eurasian Journal of Educational Research, Turkey, n. 63, p. 205-224, jan. 2016. Disponível em: https://eric.ed.gov/?id=EJ1112437. Acesso em: 30 out. 2018.

KIM, Eunyoung; BENSON, Stefanie; ALHADDAB, Taghreed A. A career in academia?:

Determinants of academic career aspirations among $\mathrm{PhD}$ students in one research university in the US. Asia Pacific Education Review, Seoul, v. 19, n. 2, p. 273-283, jun. 2018. Disponível em: https://link.springer.com/article/10.1007\%2Fs12564-018-9537-6. Acesso em: 30 out. 2019.

KITCHENHAM, Barbara. Procedures for Performing Systematic Reviews. Keele University Technical Report TR/SE-0401. Keele (UK): Keele University, jul. 2004. 
KUENZER, Acácia Zeneida. A formação dos profissionais da educação: proposta de diretrizes curriculares nacionais. Revista Educação, v. 25, n. 1, p. 67-83, 2000. Disponível em: https://periodicos.ufsm.br/reveducacao/article/view/4777. Acesso em: 02 nov. 2018.

KUENZER, Acácia Zeneida. Competência como práxis: os dilemas da relação entre teoria e prática na educação dos trabalhadores. Boletim Técnico do SENAC, v. 29, n. 1, p. 17-27, 2003. Disponível em: https://www.bts.senac.br/bts/article/view/501. Acesso em: 02 nov. 2018.

MARQUES, Joana Brás Varanda; FREITAS, Denise de. Método DELPHI: caracterização e potencialidades na pesquisa em Educação. Pro-Posições, Campinas, v. 29, n. 2, p. 389-415, ago. 2018. Disponível em: http://www.scielo.br/scielo.php?script=sci_arttext\&pid=S0103-

73072018000200389\&lng=pt\&nrm=iso. Acesso em: 07 nov. 2019.

MARQUES, Roberta Smania. Em Busca do Desenvolvimento de Competências Didático-Pedagógicas no Contexto da Formação Inicial de Docentes em Ciências Biológicas. 2017. 282 f. Tese (Doutorado em Ensino, Filosofia e História das Ciências). Salvador: Universidade Federal da Bahia, 2017.

MAULANA, Ridwan; HELMS-LORENZ, Michelle, IRNIDAYANTI, Yulia; GRIFT, Wim van de. Autonomous Motivation in the Indonesian Classroom: Relationship with Teacher Support Through the Lens of Self-Determination Theory. Asia-Pacific Education Researcher, Singapore, v. 25, n. 3, p. 441451, jun. 2016. Disponível em: http://link.springer.com/article/10.1007/s40299-016-0282-5. Acesso em: 30 out. 2019.

MEDEIROS, Mario. Lógicas das competências: Perspectivas para o Currículo em Ação. Revista Latinoamericana de Ciencias Sociales, Niñezy Juventud, Colômbia, v. 14, n. 2, p. 1031-1040, jul. 2016. Disponível em: http://revistaumanizales.cinde.org.co/rlcsnj/index.php/Revista-

Latinoamericana/article/view/2589. Acesso em: 30 out. 2018.

MORANDI, Maria Isabel Wolf Motta; CAMARGO, Luis Feliz Riehs, Revisão sistemática da literatura. In: DRESCH, Aline; LACERDA, Daniel Pacheco de; ANTUNES JUNIOR, José Antonio Valle. Design Science Research: método e pesquisa para avanço da ciência e da tecnologia. Porto Alegre: Bookman, 2015.

OLIVEIRA, Andressa Paula de. Considerações acerca das políticas públicas de formação docente no Brasil e no Espirito Santo em perspectiva histórica. 2017. 116 f. Dissertação (Mestrado em Ensino na Educação Básica). São Mateus: Universidade Federal do Espírito Santo, 2017.

OLIVEIRA, Francine de Couto de. O Papel da Revista Competência na Formação do Educador Enquanto Intelectual Orgânico: limitações e potencialidades. 2017. 128 f. Dissertação (Mestrado Profissional em Educação e Tecnologia). Pelotas: Instituto Federal De Educação, Ciência e Tecnologia Sul-RioGrandense, 2017.

PERRENOUD, Philippe. Construir Competências Desde a Escola. Tradução de Bruno Charles Magne. Porto Alegre: Artes Médicas Sul, 1999.

PERRENOUD, Philippe. Dez Novas Competências para Ensinar. Tradução de Patrícia Chittoni Ramos. Porto Alegre: Artmed, 2000.

RAMOS, Altina; FARIA, Paulo Manoel; FARIA, Ádila. Revisão sistemática de literatura: contributo para a inovação na investigação em Ciências da Educação. Revista Diálogo Educacional, Curitiba, v. 14, n. 41, p. 17-36, jul. 2014. ISSN 1981-416X. Disponível em: 
https://periodicos.pucpr.br/index.php/dialogoeducacional/article/view/2269/2185. Acesso em: 27 ago. 2018.

RATINAUD, Pierre. Iramuteq:R Interface para Análises Multidimensionais de Textos e Questionários. Version 0.7 alpha 2. Toulouse: LERASS - Le Laboratoire D'Études Et de Recherches Appliquées En Sciences Sociales, 2014. Disponível em: http://www.iramuteq.org. Acesso em: 02 nov. 2018.

RIE, Kay; RYAN, Stephen; SARAH, Mercer. Using Q Methodology to Investigate Pre-Service EFL Teachers'Mindsets about Teaching Competences. Studies in Second Language Learning and Teaching, Austria, v. 8, n. 3, p. 572-598, jan. 2018. Disponível em: http://eric.ed.gov/?id=EJ1188846. Acesso em: 30 out. 2018.

SAMPAIO, Rosana F.; MANCINI, M.C. Estudos De Revisão Sistemática: Um Guia para Síntese Criteriosa da Evidência Científica. Revista Brasileira de Fisioterapia, São Carlos, v. 11, ed. 1, p. 83-89, jan./fev. 2007.

SERGIS, Stylianos; SAMPSON, Demetrios G. Learning Object Recommendations for Teachers Based on Elicited ICT Competence Profiles. Ieee transactions on learning technologies, New Jersey, v. 9, n. 1, p. 6780, jan. 2016. Disponível em: https://ieeexplore.ieee.org/stamp/stamp.jsp?arnumber $=7109912$. Acesso em: 29 out. 2018.

SEVERO, José Leonardo Rolim de Lima. Formação e Profissionalidade Docente: A Pedagogia como Base de Saberes e Competências do Professor. Revista Reflexão e Ação, Santa Cruz do Sul, v. 24, n. 2, p. 261-279, maio 2016. Disponível em: https://online.unisc.br/seer/index.php/reflex/article/view/4695. Acesso em: 31 out. 2018.

SILVA, Luciana de Oliveira. Competência tecnológica em foco: a prática de ensino com apoio de ambientes virtuais. Revista Ilha Desterro, v. 69, n. 1, abr. 2016.

TARDIF, Maurice. Saberes Docentes e Formação Profissional. Edição Digital. Petrópolis: Editora Vozes, 2014.

URZEDO, Fabiana Pádua de. A Formação Docente Continuada na Universidade Federal de Uberlândia à luz. das Competências Profissionais. 2017. 183 f. Dissertação (Mestrado Profissional em Gestão Organizacional). Uberlândia: Universidade Federal de Uberlândia, 2017.

ZARIFIAN, Philippe. Le cas concret de l'application d'une démarche Compétence: le cas de la CNAMTS. site personnel Philippe Zarifian, 2011. Disponível em: http://philippe.zarifian.pagespersoorange.fr/page55.htm. Acesso em: 02 nov. 2018.

ZARIFIAN, Philippe. Le travail et la compétence: entre puissance et contrôle. Paris: PUF, 2009.

ZARIFIAN, Philippe. O modelo da competência: trajetória histórica, desafios atuais e propostas. São Paulo: SENAC, 2003. 